\title{
A Study on the Use of Massive Open Online Courses in Otorhinolaryngology After Graduation
}

\author{
Hülya Eyigör ${ }^{1}$ (D), Erol Gürpınar ${ }^{2}$ (1) \\ ${ }^{1}$ Department of Otorhinolaryngology and Head and Neck Surgery, University of Health Sciences Antalya Training and Research \\ Original Investigation \\ Hospital, Antalya, Turkey \\ ${ }^{2}$ Department of Medical Education, Akdeniz University School of Medicine, Antalya, Turkey
}

Abstract

ORCID IDs of the authors:

H.E. 0000-0001-5317-431X;

E.G. 0000-0002-5544-7040

Cite this article as: Eyigör H, Gürpınar E. A Study on the Use of Massive Open Online Courses in Otorhinolaryngology After

Graduation. Turk Arch Otorhinolaryngol 2019; 57(4): $171-5$

This paper was presented at the National Symposium of Medical Education held between 10-12 April 2019 in Turkey.

\section{Corresponding Author:}

Hülya Eyigör, hulinar@yahoo.com

Received Date: 27.06.2019

Accepted Date: 18.09.2019

Content of this journal is licensed under a Creative Commons Attribution 4.0 International License. Available online at www.turkarchotolaryngol.net
Objective: The use of massive open online courses (MOOCs) in medical education and postgraduate education is becoming more and more widespread across the world. A survey study was carried out in Turkey to collect information and raise awareness about the use of MOOCs for educational and training purposes in the field of otorhinolaryngology after graduation.

Method: The prepared survey questionnaire was published on the online communication platform of the Turkish Otorhinolaryngology-Head and Neck Surgery Association, and volunteers were asked to fill-out the questionnaire by clicking the given link.

Results: A total of 210 volunteers participated in the survey study. Most of the volunteers (26.2\%) were in the $36-40$ age range. At the time of the study $53.8 \%$ of the volunteers were working as specialist doctors,
$19.5 \%$ as residents, $10.5 \%$ as professors, $8.1 \%$ as associate professors, and $8.1 \%$ as assistant professors. Only 19 (9\%) respondents ticked "yes" in response to the question "Are you familiar with the MOOC programs?" and only six (2.9\%) of these respondents had attended a MOOC program. Evaluation of the correlation between academic title and awareness of MOOC programs showed that the instructors had a significantly higher level of MOOC awareness compared to the specialists and the residents $(\mathrm{p}=0.032)$.

Conclusion: Results of the survey revealed that the use of MOOC programs in postgraduate otorhinolaryngology education was low and the volunteers were not well-informed about this practice.

Keywords: Online learning, postgraduate education, otorhinolaryngology, internet

\section{Introduction}

Open and distant learning is advocated as an educational system to address the information needs of the globalizing and transforming society. The most appealing trait of such programs is that they offer an extensive educational model where individuals can willingly create their course content anywhere and anytime and are able to create discussion platforms with others if they wish to do so (1). Massive Open Online Courses (MOOCs) constitute an educational model where individuals access information selectively without having to be enrolled at a university, pay tuition fees or join an undergraduate program. The word massive does not only denote the huge number of learners but also the creation of global, mega classes that extend beyond the borders of the physical campus. The word open refers to the accessibility of the courses for everyone. The word online signifies that the courses are delivered via the internet, leveraging the benefits offered by information and communication technologies. As for the last word of MOOC, courses, this means that the learning and teaching activities take place within the framework of a process that relies on an academical schedule and is based on pedagogic foundations. The aim of this model is to enable large-scale and high-quality open learning and to provide more cost-efficient educational services (2). Today, some of the most frequently visited Internet addresses for massive open line courses are Coursera (California, USA), Edx (USA), Udacity (USA), FutureLearn (Milton Keynes, England), Codeacademy (New York, USA), OpenLearning (Sydney, Australia), NPTEL (India), Khan Acade- 
my (California, USA), Udemy (California, USA), and ALISON (Galway, Ireland). The use of MOOCs in medical and postgraduate education is becoming more and more widespread throughout the world. In the literature, however, there is a small number of studies from Turkey that address the use of MOOCs in medical and postgraduate education.

The aim of the presented study is to investigate how well otorhinolaryngology residents and specialists are informed about MOOCs, to determine their usage intensity of MOOCs, and to raise awareness about MOOCs.

\section{Methods}

Since the study is focused on determining the needs, it was designed cross-sectional. The study was approved by the Clinical Research Ethics Committee of Akdeniz University School of Medicine (2012-KAEK-20 /86-2018). The study was explained to all participants and their informed consent was obtained prior to the study.

The study aimed to reach otorhinolaryngology doctors from all geographic regions and institutions (i.e., university hospitals, training and research hospitals, public hospitals and private hospitals) of Turkey. The target population of the study consisted of otorhinolaryngology residents, specialists and academicians (assistant professors, associate professors and professors). A sample group was not specified.

Data were collected from the participants who volunteered to fill-out the survey form. The questionnaire was delivered to the

$21-25$
$26-30$
$31-35$
$36-40$
$41-50$
$51-55$
$56-60$
60 and above

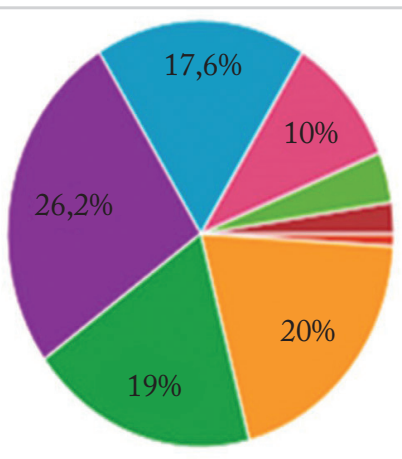

Figure 1. Age distribution of the participants

Table 1. Responses of participants to the question, "Which social media platforms do you use to further educate yourselves on otorhinolaryngology?"

\begin{tabular}{l|c|c}
\hline Social Media Users & Number & Rate (\%) \\
\hline Multiple websites & 99 & 47.1 \\
\hline YouTube & 47 & 22.4 \\
\hline Facebook & 5 & 2.4 \\
\hline WhatsApp & 4 & 1.9 \\
\hline Medical websites & 2 & 1 \\
\hline Those who do not use social media & 53 & 25.2 \\
\hline TOTAL & 210 & 100 \\
\hline
\end{tabular}

study group via the web page and by e-mail on March 12, 2018 and then once again on August 20,2018. The online survey form included a short introductory section about the objectives of the study, precise information about MOOCs, the participants' demographic characteristics, and 13 questions about MOOCs. The participants were asked to fill-out the questionnaire by clicking on the survey link on the otorhinolaryngology platform, which serves as a communication channel for nearly 3,000 otorhinolaryngologists. The link was active from March 12 to August 20, 2018.

\section{Statistical Analysis}

Statistical analyses using the chi-square test were conducted using Statistical Package for Social Sciences (IBM Corp.; Armonk, NY, USA) for Windows version 18.0. The results were evaluated at the $95 \%$ confidence level and $\mathrm{p}<0.05$ was considered significant.

\section{Results}

Two hundred-ten otorhinolaryngologists volunteered to participate in the study. Of the participants, $69 \%$ were female and $31 \%$ were male. The age distribution of the volunteers is shown on Figure 1.

At the time of the study $34.8 \%$ of the volunteers were working at training and research hospitals, $28.6 \%$ at university hospitals, $21 \%$ at public hospitals, $11 \%$ at private hospitals and the remaining $4.6 \%$ were in private practice. A great majority of the volunteers had graduated from medical school about six to 10 years ago. Of the volunteers, $53.8 \%$ (113) were specialists, $19.5 \%$ (41) were residents, $10.5 \%$ (22) were professors, $8.1 \%$ (17) were associate professors and 8.1\% (17) assistant professors.

Of the participants, $74.8 \%$ responded "yes" to the question "Do you use social media (e.g., Facebook, Twitter, YouTube, WhatsApp) to further educate yourself on otorhinolaryngology?" While $47 \%$ stated that they generally used multiple social media networks (Facebook, Twitter, YouTube), 22.4\% indicated YouTube as their second most used social media network ( $\mathrm{Ta}-$ ble 1). Out of the 156 volunteers who responded to the question "How often do you use social media for self-education?" $41 \%$ ticked "once a week," 35.3\% "every day," and 23.7\% "once a month.”

As for the question "How do you use the social media to further educate yourself on otorhinolaryngology?" most of the participants indicated that they watched surgery videos on the social media. The remaining responses are shown on Figure 2.

One hundred ninety-one participants (91\%) responded "no" to the question "Are you familiar with the MOOC programs?" and only 19 (9\%) ticked "yes."

Only six participants (2.9\%) responded "yes" to the question "Have you ever attended a MOOC program?" The MOOC programs that these respondents attended are shown in Figure 3. 
Table 2. Responses of participants to the statements related to the use of MOOCS for postgraduate otorhinolaryngology education

\begin{tabular}{|c|c|c|c|c|c|}
\hline & $\begin{array}{c}\text { Definitely } \\
\text { disagree }\end{array}$ & $\begin{array}{l}\text { Do not } \\
\text { agree }\end{array}$ & $\begin{array}{l}\text { Not } \\
\text { sure }\end{array}$ & Agree & $\begin{array}{l}\text { Definitely } \\
\text { agree }\end{array}$ \\
\hline The fact that MOOCs are accessible from everywhere is a reason of preference & $10(4.8 \%)$ & $2(1 \%)$ & $28(13.3 \%)$ & $35(16.7 \%)$ & $135(64.3 \%)$ \\
\hline MOOCs are reliable & $8(3.8 \%)$ & $10(4.8 \%)$ & $86(41 \%)$ & $51(24.3 \%)$ & $55(26.2 \%)$ \\
\hline I am more likely to participate in MOOCs since they are free of-charge & $2(0.9 \%)$ & $3(1.4 \%)$ & $9(4.3 \%)$ & $27(12.9 \%)$ & $169(80.5 \%)$ \\
\hline I would prefer courses that offer certification & $7(3.3 \%)$ & $8(3.8 \%)$ & $35(16.7 \%)$ & $39(18.6 \%)$ & $121(57.6 \%)$ \\
\hline Students could benefit from MOOCs more if there were mid-term exams in the courses & $7(3.3 \%)$ & $12(5.7 \%)$ & $43(20.5 \%)$ & $56(26.7 \%)$ & $92(43.8 \%)$ \\
\hline I would prefer courses from Turkey & $12(5.7 \%)$ & $12(5.7 \%)$ & $60(28.6 \%)$ & $52(24.8 \%)$ & $74(35.2 \%)$ \\
\hline I would prefer courses from abroad & $11(5.2 \%)$ & $23(11 \%)$ & $77(36.7 \%)$ & $44(21 \%)$ & $55(26.2 \%)$ \\
\hline MOOCs are convenient for postgraduate medical education & $4(1.9 \%)$ & $4(1.9 \%)$ & $43(20.5 \%)$ & $52(24.8 \%)$ & $107(51 \%)$ \\
\hline MOOCs should be used as a criterion for academic career progress & $42(20 \%)$ & $33(15.7 \%)$ & $70(33.3 \%)$ & $24(11.4 \%)$ & $41(19.5 \%)$ \\
\hline After this survey I plan to enroll in a MOOC program & $11(5.2 \%)$ & $8(3.8 \%)$ & $64(30.5 \%)$ & $47(22.4 \%)$ & $80(38.1 \%)$ \\
\hline
\end{tabular}

MOOC: massive open online course; MOOCs: massive open online courses

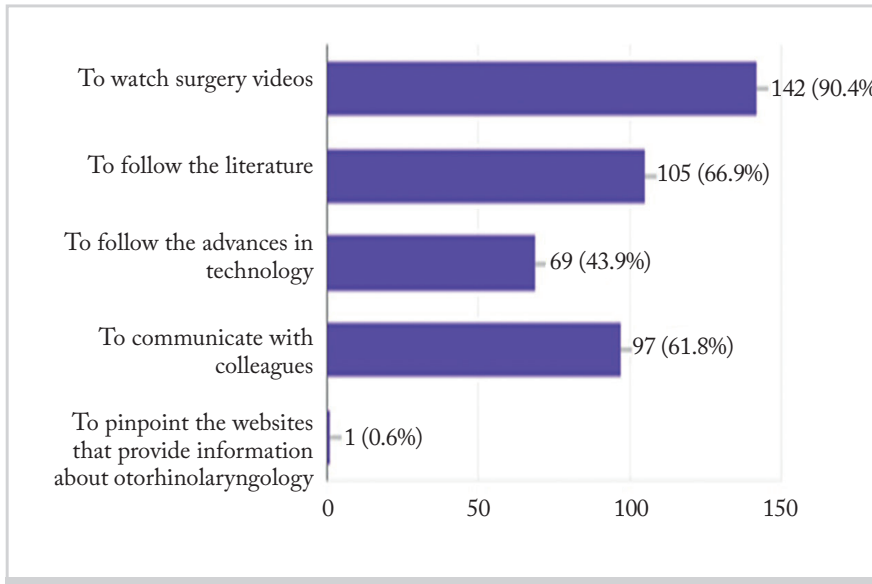

Figure 2. Responses of participants to the question "How do you benefit from the social media to further educate yourself on otorhinolaryngology?"

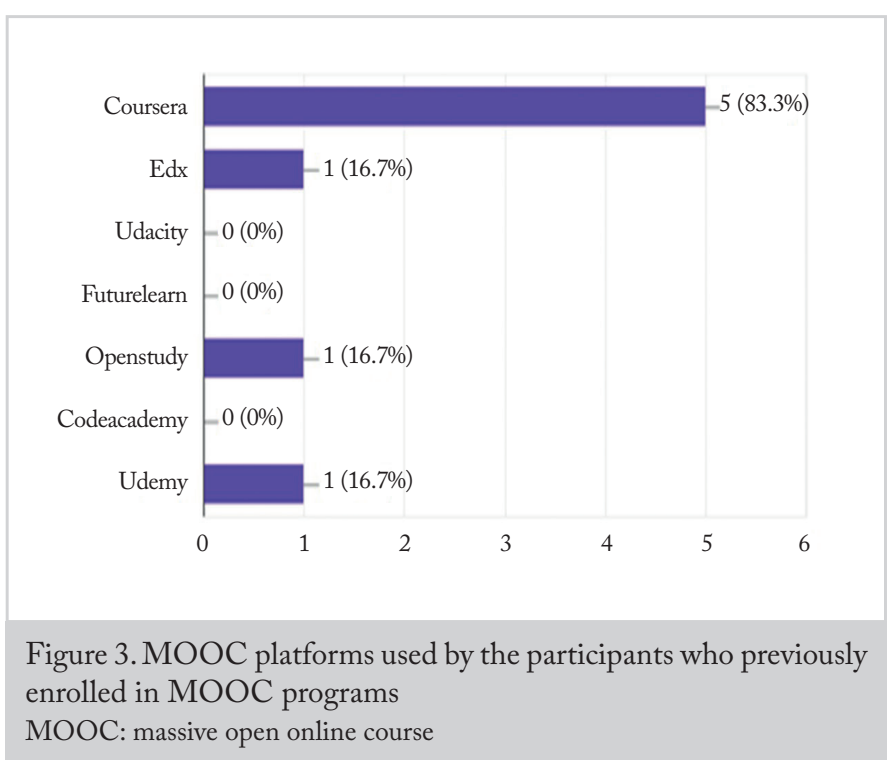

Of the six participants who stated that they previously attended MOOC programs, 83.6\% responded "yes" and the remaining 16.7\% "no" to the question "Did you benefit from the MOOC program(s) you attended?" As for the question "How many hours a week did
Table 3. The relation between MOOC awareness and academic career

\begin{tabular}{l|c|c|c}
\hline \multirow{2}{*}{} & \multicolumn{2}{|c|}{$\begin{array}{c}\text { Are you informed about } \\
\text { MOOC programs? }\end{array}$} & \multirow{2}{*}{ Total } \\
\cline { 2 - 4 } & Yes & No & To \\
\hline Specialists and Residents & $10(6.5 \%)$ & $144(93.5 \%)$ & $154(73.3 \%)$ \\
\hline Academicians & $9(16 \%)$ & $47(84 \%)$ & $56(26.7 \%)$ \\
\hline Total & $19(9 \%)$ & $191(91 \%)$ & $210(100 \%)$ \\
\hline MOOC: massive open online course & & &
\end{tabular}

you spend on MOOCs?" four of the six participants responded, "less than one hour a week," and the remaining two responded "two to six hours a week." Only two of the six participants who had attended MOOCs stated that they completed their MOOC program. These two participants stated that "the long duration of the course programs" was the reason why they could not complete their courses. None of the six participants responded "yes" to the question "Did you get a certificate from the MOOCs you completed?"

After a brief explanation about MOOC programs, the participants were asked about their opinion on the use of MOOCs in postgraduate otorhinolaryngology studies. Their responses are shown in Table 2.

Since the number of the participants who had previously used MOOCs was low, the statistical evaluation was based on their awareness of MOOC platforms. There were no statistical differences in terms of gender or the educational institutions where they completed their residency programs $(p=0.647, p=0.774$, respectively) among the participants who were familiar with MOOC programs prior to the study. When participants were grouped by age as older and younger than 45 years, a statistically significant difference was not found between the two groups in terms of their familiarity with MOOC programs $(p=0.770)$. The evaluation of the relationship between awareness of MOOCs and academic titles showed that instructors were significantly more aware of the MOOC programs compared to the rest of the group $(\mathrm{p}=0.032)$ (Table 3$)$. 


\section{Discussion}

In our study, $74.8 \%$ of the volunteers reported that they did not use any social media networks to further educate themselves in otorhinolaryngology after graduation. According to the literature, Facebook is used by $64-96 \%$ of the otorhinolaryngology medical students and $13-47 \%$ of the otorhinolaryngology specialists for educational purposes (3). Avc1 et al. (4) reported that 89.3\% of medical students in Turkey use social media for educational purposes. According to the findings of our study, the social media platform most frequently used for postgraduate education among the participants is YouTube. We believe that this result is particularly associated with the fact that otorhinolaryngology is a surgical branch and it is possible to watch surgery videos on the video platforms. The volunteering participants stated that they predominantly used social media to communicate with their colleagues and follow the latest advancements in technology and the updates in the literature.

While some educators see MOOC platforms as a threat against conventional learning, others advocate that these platforms can serve as a complementary tool (5). Some authors argue the majority of students on MOOCs are already well educated compared with the general population (6). One of the rare studies investigating the use of MOOCs in the field of medicine was conducted by Clark et al. (7) and focused on the use of MOOCs and its implications in medical imaging education. The authors reported that MOOC programs motivated the students, contributed to their skills and directed them to life-long learning. The low use of MOOCs among otorhinolaryngologists can be explained by the lower number of MOOC programs in medicine compared to other fields and the lack of information about these programs in the healthcare community. Of the respondents who stated to have previously benefited from MOOCs, three were specialists and three were academicians (two professors, one asociate professor). These six individuals were aged between 31 and 55 years. When this result is evaluated from the perspective of awareness about MOOC programs, the statistically higher levels of awareness among individuals with higher academic positions can be explained by two reasons. First, there might be high interest in these courses in the academic working environment. Second, academicians might have the tendency to use these platforms to update their knowledge on latest medical developments. With the assumption that younger doctors would be more likely to use the internet, we investigated the relation between age and MOOC awareness and determined that age was not a statistically significant factor.

After 6-week-long MOOC study group sessions, Chen et al. (8) concluded that MOOCs broadened the students' perspective of thinking, enhanced their cultural awareness and learning motivation. Additionally, the authors stated that, in the study group sessions, the students built a strong sense of community by sharing their ideas openly and by helping each other. Cole and Timmerman (9) studied 84 undergraduate students attending MOOCs in various fields. Fourteen of the students included in the study stated that although they believed that MOOCs contributed to life-long learning, they were doubtful about the reliability of the information presented and online communication had its own difficulties. Moreover, the students stated that when attending MOOCs, they were devoid of the advantages of asking their classmates for help, discussing about the lessons and getting help from the educators personally. They also indicated that the high number of students attending the course prevented them from establishing one-on-one interaction with the lecturer (9). The experiences of the participants were not questioned in our study since the number of the participants who had previously attended MOOC programs was low. Instead, after informing the participants about MOOC platforms, a question was asked about the reliability of MOOCs, and about half of the participants $(50.5 \%)$ agreed that they could be reliable. Of the participants, $93.4 \%$ stated that the foremost reason for them to prefer MOOCs was that they were free-of-charge. However, $69 \%$ of the participants were against or undecisive about using MOOC programs as a criterion for academic career progress.

Review of the literature shows that while MOOC programs are becoming increasingly popular, low completion rates remain as a problem (10). Completion rate of these programs among students has been reported to be lower than $10 \%$. According to the literature, the foremost reason that attendees do not complete the courses were the lack of online support systems and students' greater focus on the content instead of certificates or grades (11). The long duration of the programs, which was reported as one of the reasons for incompletion in the literature, was also a factor in the present study for leaving the course. In our study, the participants who previously attended MOOCs reported that they used MOOCs less than one hour in a week. A recent study compared the number of students attending MOOCs and their completion rate (less than 10\%) and showed that high incompletion rates constituted a problem for most MOOC programs (12). In our study, we determined that only two out of the six participants who previously attended MOOCs had completed the program and neither of them obtained their certificate. A study showed that a program lasting just 4.5 hours a week proved to be an effective educational tool even for clinicians with too busy work schedules (13). In our study, many of the participants who previously attended MOOC programs reported that they spent less than one hour a week on these programs.

The number of MOOCs related to health and medicine education increases every year. It has been reported that MOOCs could especially be useful for physicians working in the peripheral cities of developing countries by providing continuous medical education (14). In their study investigating courses in the fields of health and medicine, Liyanagunawardena and Williams (15) reported that academically these courses were at introductory level. Since these programs target a wide audience, the simplified presentation of the content may be frustrating for individuals who expect an academic level of education.

The limitation of our study is the low number of people who volunteered to respond to the survey despite the large sample universe. Thus, the results of this study fall short of thoroughly reflecting the views of the Turkish otorhinolaryngologists. Fur- 
thermore, the survey did not include open-ended questions that enable qualitative evaluation.

\section{Conclusion}

While MOOC programs direct individuals to life-long learning, the high rates of incompletion of the courses, the lack of online support systems, and the non-standardized quality of education offered by MOOCs are considered as their downsides. Although our study showed that the use of, as well as the awareness about MOOCs in postgraduate otorhinolaryngology education is low in Turkey, one of the goals of the study was to increase the awareness about these programs, and thereby to incite the use of these platforms and the establishment of such models in the field of medical education in Turkey.

Ethics Committee Approval: Ethics committee approval was received for this study from the Ethics Committee of Akdeniz University School of Medicine (2012-KAEK-20 /86-2018).

Informed Consent: Written informed consent was obtained from the patients who participated in this study.

Peer-review: Externally peer-reviewed.

Author Contributions: Concept - H.E. E.G.; Design - H.E. E.G.; Supervision - E.G.; Fundings - H.E.; Materials - H.E. E.G.; Data Collection and/or Processing - H.E. E.G.; Analysis and/or Interpretation - H.E. E.G.; Literature Review - H.E., E.G.; Writing - H.E.; Critical Reviews - E.G.

Conflict of Interest: The authors have no conflicts of interest to declare.

Financial Disclosure: The authors declared that this study has received no financial support.

\section{References}

1. Stracke CM. How can e-learning and MOOCs reveal and exploit the hidden treasures of open research and open education? In: Teixeira AM, Szűcs A, Mázár, I, editors. From education to employment and meaningful work with ICTs. Proceedings of EDEN Annual Conference. Zagreb: European Distance and E-Learning Network; 2014: p 11.
2. Kop R. The challenges to connectivist learning on open online networks: learning experiences during a massive open online course. IRRODL. 2011; 12: 19-38. [CrossRef]

3. von Muhlen M, Ohno-Machado L. Reviewing social media use by clinicians. J Am Med Inform Assoc 2012; 19: 777-81. [CrossRef]

4. Avcı K, Çelikden SG, Eren S, Aydenizöz D. Assessment of medical students' attitudes on social media use in medicine: a cross-sectional study. BMC Med Educ 2015; 15: 18. [CrossRef]

5. Bergh AM, Bac M, Hugo J, Sandars J. "Making a difference" Medical students' opportunities for transformational change in health care and learning through quality improvement projects. BMC Med Educ 2016; 16: 171. [CrossRef]

6. Emanuel EJ. Online education: MOOCs taken by educated few. Nature 2013; 503: 342. [CrossRef]

7. Clark KR, Vealé BL, Watts LK. A review of the use of massive open online courses (MOOCs) in medical imaging education. IJAHSP 2017; 15: 1-6.

8. Chen YH, Chen PJ. MOOC study group: facilitation strategies, influential factors, and student perceived gains. Comput Educ 2015; 86: 55-70. [CrossRef]

9. Cole AW, Timmerman CE. What do current college students think about MOOCs? MERLOTJ Online Learn Teach 2015; 11 : 188-201.

10. Robinson R. Insights from a massive open online course (MOOC) for medical education (2014-2018) PeerJ Preprints 6:e26879v1. [CrossRef]

11. El-Hmoudova D.MOOCs motivation and communication in the cyber learning environment. Procedia - Soc Behav Sci 2014; 131: 29-34. [CrossRef]

12. Bozkurt A, Akgün-Özbek E, Zawacki-Richter O. Trends and patterns in massive open online courses: review and content analysis of research on MOOCs (2008-2015). Int Rev Res Op Dis Lear 2017; 18: 118-47. [CrossRef]

13. Subhi Y, Andresen K, Rolskov Bojsen S, Mørkeberg Nilsson P, Konge L. Massive open online courses are relevant for postgraduate medical training. Dan Med J 2014; 61: A4923.

14. Culquichicón C, Helguero-Santin LM, Labán-Seminario LM, Cardona-Ospina JA, Aboshady OA, Correa R. Massive open online courses in health sciences from Latin American institutions: a need for improvement? F1000Res 2017; 6: 940. [CrossRef]

15. Liyanagunawardena TR, Williams SA. Massive open online courses on health and medicine: review .J Med Internet Res 2014; 16: e191. [CrossRef] 